\title{
PENGARUH VARIABEL MAKRO TERHADAP NILAI TUKAR RUPIAH ATAS DOLAR AS PERIODE 2012-
} 20151)

\author{
Yessica Tri Permatasari \\ Mahasiswa Program Studi S1 Ekonomi Islam Fakultas Ekonomi dan Bisnis Universitas Airlangga \\ Surabaya \\ Email: yessica.tri-12@feb.unair.ac.id \\ Suherman Rosyidi \\ Departemen Ekonomi Islam Fakultas Ekonomi dan Bisnis Universitas Airlangga Surabaya \\ Email: s_herman@telkom.net
}

\begin{abstract}
The aim of this research was to determine the influence of money supply, reward for Indonesian sharia Bank certificate (SBIS), import and export to the rupiah exchange rate on the US dollar during 2012-2015. The research methods used was quantitative method with multiple linear regression analysis. The data used in this study was secondary monthly time series data in time during 2012 - 2015. Data in this research were obtained from Central Bureau of Statistic (BPS) and Indonesian Economic and Financial Statistic (SEKI). The result of this study indicate that partially, the money supply and reward for SBIS has significant impact on the rupiah exchange rate on the US dollar during 2012-2015, while import and export has no significant effect on the rupiah exchange rate on the US dollar during 2012-2015. Simultaneously, money supply, SBIS return rate, import and export had significant effect to the rupiah exchange rate on the US dollar during 2012-2015.
\end{abstract}

Keyword: Exchange Rate, Money Supply, SBIS, Export, Import

\section{PENDAHULUAN}

Perdagangan internasional adalah sarana pertukaran barang dan jasa yang melibatkan dua negara atau lebih. Dewasa ini, perdagangan internasional telah tumbuh dan berkembang secara signifikan. Perdagangan internasional merupakan bagian dari proses globalisasi. Tekanan dari perdagangan internasional merupakan salah satu fenomena perekonomian Indonesia di tahun 2012 (KSK: 21).

Perdagangan internasional ini akan menimbulkan perbedaan mata vang yang digunakan oleh negara-negara bersangkutan. Penggunaan uang fiat untuk semua transaksi perdagangan, baik dalam maupun luar negeri menimbulkan ketidakstabilan perekonomian. Nilai mata vang yang berbeda akan mengakibatkan para pelaku usaha atau bisnis memperhatikan nilai nilai tukarnya. Nilai tukar (exchange rate) adalah pertukaran antara dua mata uang yang berbeda, atau merupakan perbandingan nilai antara kedua mata vang tersebut. Nilai mata uang yang stabil menunjukkan bahwa negara tersebut memiliki kondisi ekonomi yang baik atau stabil (Sukirno, 2002:178). Stabilitas nilai mata uang harus menjadi tujuan utama kerangka referensi Islam karena penekanan Islam yang merujuk pada kejujuran dan keadilan dalam interaksi sesama manusia.

Bank Indonesia memiliki tujuan yang tertuang dalam Undang-Undang RI Nomor 23 tahun 1999 Bab III pasal 7 yaitu mencapai dan memelihara kestabilan nilai rupiah. Chapra (2000:4) menyebutkan, untuk mencapai kestabilan 
perekonomian pada sektor riil, Bank Indonesia harus menerapkan sasaran dan strategi yang tepat. Sasaran dan strategi itu salah satunya adalah stabilitas nilai vang. Stabilitas nilai mata vang dapat dijaga melalui pelaksanaan kebijakan moneter. Untuk mencapai dan memelihara kestabilan nilai rupiah yang merupakan tujuan tunggal bank Indonesia terdapat tiga pilar utama yang dilakukan, yaitu melaksanakan dan menetapkan kebijakan moneter, mengatur dan menjaga kelancaran sistem pembayaran dan melalui stabilitas sistem keuangan.

Stabilitas nilai mata uang harus menjadi tujuan utama kerangka referensi Islam karena penekanan Islam yang merujuk pada kejujuran dan keadilan dalam interaksi sesama manusia. Al-Quran dengan tegas menekankan kejujuran dan keadilan dalam semua ukuran nilai. (Chapra, 2000:4). Seperti yang tertulis dalam Al-Qur'an Surat An-Nisa: 135 berikut ini:

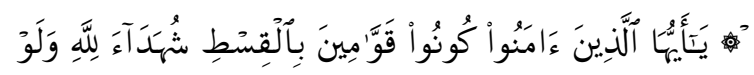

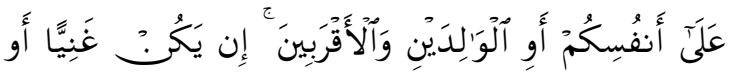

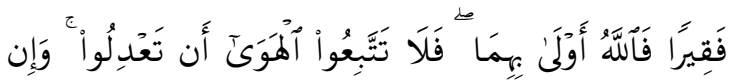

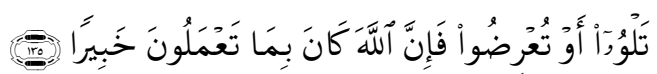

Artinya: "Wahai orang-orang yang beriman, jadilah kamu orang yang benarbenar penegak keadilan, menjadi saksi karena Allah biarpun terhadap dirimu sendiri atau ibu bapa dan kaum kerabatmu. jika ia kaya ataupun miskin, Maka Allah lebih tahu kemaslahatannya.
Maka janganlah kamu mengikuti hawa nafsu karena ingin menyimpang dari kebenaran. dan jika kamu memutar balikkan (kata-kata) atau enggan menjadi saksi, Maka Sesungguhnya Allah adalah Maha mengetahui segala apa yang kamu kerjakan". (QS. An-Nisa': 135)

Ketika sistem perbankan Indonesia mulai beralih dari sistem konvensional menjadi dual banking system, untuk mengakomodasi kehadiran bank syariah, Bank Indonesia (BI) menerbitkan instrumen moneter berbasis syariah bernama Sertifikat Wadiah Bank Indonesia (SWBI, yang kemudian diubah menjadi Sertifikat Bank Indonesia Syariah (SBIS). SBIS merupakan salah satu mekanisme yang digunakan Bank Indonesia untuk mengontrol kestabilan nilai rupiah.

Berdasarkan latar belakang masalah tersebut, maka pertanyaan yang akan menjadi fokus pada penelitian ini adalah :

1. Apakah jumlah vang beredar (JUB), imbal hasil Sertifikat Bank Indonesia Syariah (SBIS), impor, ekspor secara bersama-sama maupun secara parsial berpengaruh signifikan terhadap nilai tukar rupiah atas dolar AS pada periode Januari 2012 sampai Desember 2015?

\section{LANDASAN TEORI}

Menurut Sukirno (2006:397), "Nilai tukar valuta asing atau nilai tukar mata vang asing menunjukkan harga atau nilai mata vang suatu negara dinyatakan dalam nilai mata vang negara lain". Nilai tukar valuta asing dapat juga didefinisikan 
Permatasari, et al/Jurnal Ekonomi Syariah Teori dan Terapan Vol. 4 No. 7 Juli 2017: 587-598; PENGARUH VARIABEL MAKRO TERHADAP NILAI TUKAR RUPIAH ATAS DOLAR AS PERIODE 2012-2015

sebagai jumlah vang domestik yang dibutuhkan, yaitu banyaknya rupiah yang dibutuhkan untuk memperoleh satu unit mata vang asing. Nilai tukar valuta di antara dua negara seringkali berbeda di antara satu masa dengan masa yang lainnya.

Sistem nilai tukar yang diterapkan di Indonesia adalah sistem nilai tukar mengambang bebas (Floating Exchange Rate) adalah nilai tukar ditentukan sepenuhnya oleh pasar tanpa intervensi dari pemerintah. Pada kondisi nilai tukar mengambang, nilai tukar dibiarkan bergerak sesuai dengan kondisi penawaran dan permintaan mata vang yang terjadi di pasar. Dengan demikian, nilai tukar akan menguat apabila terjadi kelebihan permintaan, dan sebaliknya nilai tukar akan melemah apabila terjadi kelebihan penawaran yang terjadi di pasar valuta asing. Bank sentral dapat melakukan intervensi di pasar valuta asing dengan menjual devisa atau membeli devisa apabila terjadi kekurangan atau kelebihan penawaran untuk menghindari fluktuasi nilai tukar yang berlebihan (Triyono, 2005).

Kebijakan nilai tukar uang dalam Islam dapat dikatakan menganut sistem mengambang terkendali (Managed Floating), dimana nilai tukar adalah hasil dari kebijakan-kebijakan pemerintah karena pemerintah tidak mencampuri keseimbangan yang terjadi di pasar kecuali terjadi hal-hal yang mengganggu keseimbangan itu sendiri (Abdurrahman, 2001:56). Jadi, nilai tukar yang stabil merupakan hasil dari kebijakan pemerintah yang tepat.

Menurut dasar pikiran ekonomi Keynes dalam buku Ekonomi Moneter (Nopirin, 1987:173), faktor-faktor yang mempengaruhi permintaan dan penawaran nilai tukar valuta asing adalah pendapatan, harga, dan tingkat bunga. Untuk itu semua kegiatan ekonomi dan kebijakan pemerintah (moneter dan fiskal) yang mempengaruhi pendapatan, harga, serta tingkat bunga secara tidak langsung akan mempengaruhi nilai tukar.

Jumlah vang beredar (JUB) atau yang disebut penawaran uang (money supply) adalah jumlah nilai keseluruhan uang yang berada di tangan masyarakat dan beredar dalam perekonomian suatu negara. Semakin tinggi vang beredar domestik akan menyebabkan mata vang domestik terdepresiasi (Mishkin, 2008:130). Dari pernyataan tersebut maka, dapat disimpulkan jika jumlah vang yang beredar terlalu besar maka masyarakat akan lebih banyak menggunakannya untuk proses transaksi sehingga menyebabkan kenaikan harga barang di dalam negeri. Apabila harga yang tinggi di dalam negeri dibanding luar negeri maka masyarakat domestik lebih suka membeli barang dari luar negeri (impor), sehingga menyebabkan mata vang rupiah akan melemah atau terdepresiasi.

Menurut PBI No. 10/11/PBI/2008, Sertifikat Bank Indonesia Syariah (SBIS) adalah salah satu instrumen yang digunakan Bank Indonesia untuk mengontrol kestabilan nilai Rupiah. SBIS 
merupakan surat berharga dalam mata vang rupiah yang diterbitkan Bank Indonesia sebagai pengakuan utang jangka pendek, dan ini merupakan salah satu instrumen yang digunakan dalam kebijakan Operasi Pasar Terbuka (OPT).

Bank Indonesia menerbitkan dan menjual SBIS untuk menyerap kelebihan jumlah vang primer yang beredar (bi.go.id). Ketika imbal hasil SBIS tinggi maka masyarakat akan tertarik untuk mengalokasikan dananya pada investasi jangka pendek SBIS. Jika permintaan SBIS naik maka, jumlah uang beredar akan berkurang sehingga dapat menekan permintaan masyarakat akan barang lyang merupakan faktor penyebab terjadinya demand pull-inflation) sehingga tingkat inflasi dapat ditekan.

Transaksi ekspor merupakan transaksi penjualan barang dan jasa dari Indonesia ke luar negeri yang berakibat pada adanya pembayaran dari pembeli di luar negeri (Sukirno, 2005:204). Hal ini berarti akan terdapat uang masuk ke dalam negeri dalam mata vang asing, sehingga eksportir harus menukarkan vang yang diperolehnya dengan mata vang dalam negeri agar dapat digunakan sebagai modal.

Menurut Nachrowi dan Usman (2006:443), ekspor merupakan salah satu sumber devisa negara. Semakin tinggi ekspor akan mengakibatkan semakin tingginya permintaan terhadap rupiah sehingga nilai tukar rupiah akan menguat/apresiasi.
Impor yaitu barang dan jasa yang masuk ke suatu negara. Setiap negara berusaha untuk mencapai surplus perdagangan/kelebihan ekspor atas impor dan menghindari defisit perdagangan kelebihan impor atas ekspor (Samuelson dan Nordhaus, 2004:302).

Menurut Nachrowi dan Usman (2006:443), "semakin tinggi impor maka akan semakin tinggi permintaan terhadap dolar Amerika, sehingga nilai tukar rupiah akan terdepresiasi". Dengan pengertian lain, peningkatan impor akan berpengaruh pada permintaan akan valuta asing sehingga menurunkan nilai tukar pada suatu negara tersebut.

\section{PENGEMBANGAN HIPOTESIS}

Dalam penelitian ini diajukan hipotesis guna memberikan arah pedoman dalam melakukan penelitian. Adapun hipotesis yang digunakan dalam penelitian ini adalah:

$H_{1}$ : Jumlah uang beredar, imbal hasil Sertifikat Bank Indonesia Syariah, impor, ekspor berpengaruh secara simultan maupun parsial dan signifikan terhadap nilai tukar rupiah atas dolar AS pada periode Januari 2012 sampai Desember 2015.

\section{METODE PENELITIAN}

\section{Pendekatan Penelitian}

Pendekatan penelitian yang digunakan dalam penelitian ini merupakan pendekatan kuantitatif. Dalam penelitian ini akan diuji apakah ada pengaruh antara jumlah vang beredar, imbal hasil sertifikat Bank 
Indonesia, impor, ekspor terhadap nilai tukar rupiah atas dolar AS. Data yang digunakan dalam penelitian ini adalah menggunakan data sekunder yang bersifat runtun waktu yang diperoleh dari BPS, SEKI dan Bank Indonesia.

\section{Devinisi Operasional}

Adapun variabel yang digunakan dalam penelitian ini yaitu jumlah vang beredar, tingkat return SBIS, ekspor dan impor. Sedangkan, variabel dependennya adalah nilai tukar rupiah atas dolar AS.

1. Nilai Tukar (Y)

Nilai tukar dapat dipresentasikan sebagai mata uang lokal yang dibutuhkan untuk membeli satu unit mata vang asing. Nilai tukar yang dipakai dalam penelitian ini adalah nilai tukar rupiah atas dolar AS, yaitu banyaknya rupiah yang dibutuhkan untuk memperoleh satu unit mata vang asing dolar AS. Data variabel nilai tukar rupiah yang digunakan merupakan data nilai tukar bulanan periode 2012 sampai 2015 dalam satuan rupiah untuk satu unit mata vang dolar AS yang diperoleh dari website resmi Bank Indonesia (www.bi.go.id).

2. Jumlah Uang Beredar $\left(X_{1}\right)$

Jumlah Uang Beredar (JUB) yaitu vang kartal (uang logam dan uang kertas) yang ada dalam peredaran, vang giral dan uang kuasi. Data variabel JUB yang digunakan yaitu jumlah vang beredar dalam arti luas (M2) selama periode 2012 sampai 2015. Data JUB diperoleh dari Badan Pusat Statistik (BPS) yang dinyatakan dalam satuan miliar rupiah serta menggunakan data bulanan.
3. Imbal Hasil SBIS $\left(X_{2}\right)$

Imbal hasil SBIS adalah tingkat pengembalian yang ditentukan oleh $\mathrm{BI}$ atas penerbitan Sertifikat Bank Indonesia Syariah dalam mengontrol peredaran vang di masyarakat. Data variabel tingkat imbal SBIS yang digunakan adalah tingkat imbal SBIS bulanan dalam satuan persen selama periode 2012 sampai 2015 diperoleh dari website resmi Bank Indonesia (www.bi.go.id).

4. Ekspor $\left(X_{3}\right)$

Ekspor adalah kegiatan mengeluarkan barang dari dalam negeri ke luar negeri. Data variabel ekspor yang digunakan adalah nilai ekspor non migas menurut jenis valuta dolar AS. Data ekspor diambil dari Statistik Ekonomi dan Keuangan Indonesia (SEKI) dalam satuan ribu Dolar AS.

5. Impor $\left(X_{4}\right)$

Impor adalah kegiatan memasukkan barang dari luar negeri ke dalam negeri. Data variabel impor yang digunakan adalah nilai impor non-migas menurut jenis valuta dolar AS. Data impor diambil dari Statistik Ekonomi dan Keuangan Indonesia (SEKI) dalam satuan ribu Dolar AS.

\section{Jenis dan Sumber Data}

Jenis data yang digunakan dalam penelitian ini adalah data sekunder time series dengan kurun waktu Januari 2012 sampai Desember 2015. Sumber data berasal dari instansi yang terkait dengan nilai tukar rupiah atas dolar AS, jumlah vang beredar (JUB), imbal hasil Sertifikat Bank Indonesia (SBIS), ekspor dan impor, 
Permatasari, et al/Jurnal Ekonomi Syariah Teori dan Terapan Vol. 4 No. 7 Juli 2017: 587-598; PENGARUH VARIABEL MAKRO TERHADAP NILAI TUKAR RUPIAH ATAS DOLAR AS PERIODE 2012-2015

yaitu Badan Pusat Statistik dan Statistik Ekonomi dan Keuangan Indonesia (SEKI) Bank Indonesia.

\section{Prosedur Pengumpulan Data}

Studi kepustakaan dengan mengumpulkan data pendukung dari literatur dan penelitian-penelitian terdahulu yang dipublikasikan untuk mengetahui gambaran mengenai masalah yang akan ditelilti. Studi kepustakaan yakni mengumpulkan data pendukung dari literatur dan penelitianpenelitian terdahulu yang dipublikasikan untuk mengetahui gambaran mengenai masalah yang akan ditelilti. Selanjutnya pengolahan data yang dilakukan dengan perangkat SPSS.

Penelitian ini menggunakan analisis bulanan dan data yang digunakan adalah sebanyak 48 observasi periode 2012 sampai 2015.

\section{Teknik Analisis}

Teknik Analisis yang digunakan dalam penelitian ini adalah analisis regresi linear berganda dengan data time series, sehingga harus memenuhi uji asumsi klasik dan uji hipotesis. Menurut Ghozali (2001:43) analisis regresi bertujuan untuk mengetahui ada atau tidaknya hubungan antara variabel dependen dengan variabel independen sekaligus untuk mengetahui besaran dan arah tanda variabel-variabel independen.

Uji asumsi klasik meliputi uji normalitas, multikolinieritas, heteroskedastisitas, dan autokorelasi. Uji hipotesis meliputi uji $t$, uji $F$, dan koefisien determinasi. Penelitian ini menggunakan tingkat signifikansi sebesar
5\% dan seluruh data diolah dengan menggunakan software SPSS.

\section{HASIL DAN PEMBAHASAN}

\section{Hasil Uji Asumsi Klasik}

1. Hasil Uji Normalitas

\section{Tabel 1}

Hasil Uji Normalitas menggunakan Kolmogorov-Smirnov Test

\begin{tabular}{|l|l|r|}
\hline \multicolumn{2}{|l|}{} & $\begin{array}{c}\text { Unstandardized } \\
\text { Residual }\end{array}$ \\
\hline $\mathrm{N}$ & 48 \\
\hline \multirow{2}{|l|}{$\begin{array}{c}\text { Normal } \\
\text { Parametersa,b }\end{array}$} & Mean \\
\cline { 2 - 3 } & $\begin{array}{l}\text { Std. } \\
\text { Deviation }\end{array}$ & 372.03683434 \\
\hline \multirow{2}{*}{$\begin{array}{c}\text { Most Extreme } \\
\text { Differences }\end{array}$} & Absolute & .108 \\
\cline { 2 - 3 } & Positive & .108 \\
\cline { 2 - 3 } & Negative & -.081 \\
\hline \multicolumn{2}{|l|}{ Kolmogorov-Smirnov Z } & .748 \\
\hline \multicolumn{2}{|l|}{ Asymp. Sig. (2-tailed) } & .630 \\
\hline
\end{tabular}

Sumber: Hasil pengolahan SPSS

Berdasarkan uji normalitas dengan one sample Kolmogorov-Smirnov test diperoleh hasil seperti pada Tabel di atas yang menunjukkan bahwa nila Asymp. Sig. sebesar 0,630. Karena nilai tersebut lebih besar dari 0,05 maka dapat disimpulkan bahwa data dari penelitian ini terdistribusi normal.

2. Hasil Uji Multikolneritas Hasil uji multikolneritas pada Tabel di bawah ini menunjukkan bahwa:

a. Nilai VIF untuk variabel Imbal Hasil SBIS (HSBIS) 4,910<10, dan Tolerance value 0,204 >0,1 maka variabel Imbal Hasil SBIS (HSBIS) dinyatakan tidak mengalami multikolneritas.

b. Nilai VIF untuk variabel Jumlah Uang Beredar (JUB) $5,557<10$, dan Tolerance value $0,180>0,1$ maka variabel Jumlah Uang Beredar (JUB) 
dinyatakan tidak mengalami multikolneritas.

c. Nilai VIF untuk variabel Ekspor 2,169< 10, dan Tolerance value $0,461>0,1$ maka di dalam variabel Ekspor dinyatakan tidak mengalami multikolneritas.

d. Nilai VIF untuk variabel Impor 1,925 < 10, dan Tolerance value $0,520>0,1$ maka di dalam variabel Impor dinyatakan tidak mengalami multikolneritas.

Tabel 2

Hasil Uji Multikolneritas

\begin{tabular}{|l|c|c|}
\hline \multirow{2}{*}{ Model } & \multicolumn{2}{|c|}{ Collinearity Statistics } \\
\cline { 2 - 3 } & Tolerance & VIF \\
\hline (Constant) & & \\
HSBIS & .204 & 4.910 \\
JUB & .180 & 5.557 \\
EKSPOR & .461 & 2.169 \\
IMPOR & .520 & 1.925 \\
\hline
\end{tabular}

Sumber: Hasil pengolahan SPSS, Lampiran

3. Hasil Uji Heteroskedastisitas

Hasil uji heteroskedastisitas pada Tabel di bawah ini menunjukkan bahwa:

a. Nilai Sig. untuk variabel Jumlah uang Beredar (JUB) 0,963 >0,05, maka pada variabel Jumlah vang Beredar (JUB) dinyatakan tidak mengalami heteroskedastisitas.

b. Nilai Sig. untuk variabel Imbal Hasil SBIS (HSBIS) 0,310 >0,05, variabel Imbal Hasil SBIS (HSBIS) dinyatakan tidak mengalami heteroskedastisitas.

c. Nilai Sig. untuk variabel Ekspor 0,402 > 0,05, maka di dalam variabel Ekspor dinyatakan tidak mengalami heteroskedastisitas. d. Nilai Sig. untuk variabel Impor 0,362 > 0,05, maka pada variabel Impor dinyatakan tidak mengalami heteroskedastisitas.

Tabel 3

Hasil Uji Heteroskedastisitas

\begin{tabular}{|l|r|r|r|r|l|}
\hline \multirow{2}{*}{ Model } & \multicolumn{2}{|c|}{$\begin{array}{l}\text { Unstandardized } \\
\text { Coefficients }\end{array}$} & $\begin{array}{r}\text { Std. } \\
\text { Coef }\end{array}$ & \multirow{2}{*}{$t$} & \multirow{2}{*}{ Sig. } \\
\cline { 2 - 4 } & \multicolumn{1}{|c|}{$\mathrm{B}$} & $\begin{array}{r}\text { Std. } \\
\text { Error }\end{array}$ & Beta & & \\
\hline Constant & 824.819 & 802.638 & & - & .310 \\
HSBIS & 2.893 & 61.944 & .015 & .047 & .963 \\
JUB & $\begin{array}{r}5.190 \mathrm{E}- \\
\text { O005 }\end{array}$ & .000 & .120 & .346 & .731 \\
EKSPOR & $\begin{array}{r}4.775 \mathrm{E}- \\
\text { O005 }\end{array}$ & .000 & .183 & .846 & .402 \\
IMPOR & $\begin{array}{r}4.722 \mathrm{E}- \\
\text { O005 }\end{array}$ & .000 & .188 & .921 & .362 \\
\hline
\end{tabular}

Sumber: Hasil pengolahan SPSS.

4. Hasil Uji Autokorelasi

Berdasarkan uji autokorelasi dengan menggunakan Durbin-Watson test, diperoleh hasil seperti di bawah ini. Nilai Durbin-Watson sebesar 0,546 menunjukkan nilai tersebut di antara -2 sampai +2 , maka dapat disimpulkan bahwa penelitian ini tidak mengalami autokorelasi.

Tabel 4

Hasil Uji Autokorelasi

\begin{tabular}{|l|c|c|r|c|c|}
\hline Model & $R$ & $R^{2}$ & $\begin{array}{c}\text { Adj } R \\
\text { Square }\end{array}$ & $\begin{array}{c}\text { Std. } \\
\text { Error }\end{array}$ & DW \\
\hline 1 & $.973 a$ & .947 & .942 & 388.96 & .546 \\
\hline
\end{tabular}

Sumber: Hasil pengolahan SPSS.

\section{Analisis Regresi Linear Berganda}

Berdasarkan Tabel di bawah ini, hasil perhitungan nilai koefisien konstanta memperlihatkan nilai sebesar 503,166. menunjukkan bahwa ketika keadaan nilai variabel independen bernilai nol, maka 
Permatasari, et al/Jurnal Ekonomi Syariah Teori dan Terapan Vol. 4 No. 7 Juli 2017: 587-598; PENGARUH VARIABEL MAKRO TERHADAP NILAI TUKAR RUPIAH ATAS DOLAR AS PERIODE 2012-2015

variabel dependen nilai tukar rupiah atas dolar AS (Y) akan bernilai positif atau mengalami kenaikan sebesar 503,166 satuan.

Tabel 5

Hasil Uji Analisis Regresi Linear Berganda

\begin{tabular}{|c|c|c|c|c|c|}
\hline \multirow{2}{*}{ Model } & \multicolumn{2}{|c|}{\begin{tabular}{|c|}
$\begin{array}{c}\text { Unstandardized } \\
\text { Coefficients }\end{array}$ \\
\end{tabular}} & \multirow{2}{*}{\begin{tabular}{|l|}
$\begin{array}{l}\text { Std. } \\
\text { Coef. }\end{array}$ \\
Beta \\
\end{tabular}} & \multirow{2}{*}{$\dagger$} & \multirow{2}{*}{ Sig. } \\
\hline & B & $\begin{array}{l}\text { Std. } \\
\text { Error }\end{array}$ & & & \\
\hline Constant & 503.166 & 1399.63 & & .360 & .721 \\
\hline HSBIS & 236.861 & 108.02 & .171 & 2.193 & \\
\hline$J U B$ & .003 & .000 & .811 & 9.762 & \\
\hline EKSPOR & $\begin{array}{l}6.167 \mathrm{E}- \\
005\end{array}$ & .000 & .033 & .627 & \\
\hline IMPOR & $\begin{array}{l}-9.679 \mathrm{E}- \\
005\end{array}$ & .000 & -.053 & -1.083 & \\
\hline
\end{tabular}

Sumber: Hasil pengolahan SPSS.

Bedasarkan hasil analisis tersebut, maka dapat diperoleh model persamaan regresi sebagai berikut:

$Y=503,166+0,003 X_{1}+236,861 X_{2}+6,16 X_{3}$

$$
-9,679 X_{4}+e .
$$

\section{Hasil Uji Hipotesis}

\section{Hasil Uji ${ }^{\dagger}$}

Berdasarkan tabel 4, diketahui hasil pengujian terhadap variabel variabel JUB nilai Sig. $<0,05$, nilai $t_{\text {hitung }}>t_{\text {tabel, }}$ maka variabel JUB berpengaruh secara signifikan dan positif terhadap variabel nailai tukar. Hasil pengujian terhadap variabel SBIS nilai Sig. $<0,05$, nilai thitung $>$ $t_{\text {tabel, }}$ maka variabel SBIS berpengaruh secara signifikan dan positif terhadap variabel nilai tukar.

Sedangkan, hasil pengujian terhadap variabel ekspor nilai Sig. $>0,05$, nilai thitung $<$ tłabel, maka variabel ekspor tidak berpengaruh terhadap variabel nilai tukar.
Hasil pengujian terhadap variabel impor nilai Sig. $>0,05$, nilai thitung $<t_{\text {tabel, }}$ maka variabel impor tidak berpengaruh terhadap variabel nilai tukar.

\section{Hasil Uji $F$}

Berdasarkan tabel 5 di bawah ini, nilai Sig. menunjukkan $<0,05$, dan nilai Fhitung $>$ Ftabel $(190,68>2,81)$. Berdasarkan hasil tersebut maka dapat ditarik kesimpulan bahwa $\mathrm{H}_{0}$ ditolak, sehingga semua variabel independen secara simultan berpengaruh secara signifikan terhadap variabel terikat.

Tabel 6

Hasil Uji $F$

\begin{tabular}{|c|c|c|c|c|c|}
\hline Model & $\begin{array}{c}\text { Sum of } \\
\text { Squares }\end{array}$ & Df & $\begin{array}{l}\text { Mean } \\
\text { Square }\end{array}$ & $F$ & Sig. \\
\hline Regression & $\begin{array}{c}11539120 \\
1.765\end{array}$ & 4 & $\begin{array}{l}288478 \\
00.441\end{array}$ & 190.7 & $.000^{\mathrm{b}}$ \\
\hline Residual & $\begin{array}{c}6505336.0 \\
87\end{array}$ & 43 & $\begin{array}{c}151286 . \\
886\end{array}$ & & \\
\hline Total & $\begin{array}{c}12189653 \\
7.852 \\
\end{array}$ & 47 & & & \\
\hline
\end{tabular}

Sumber: Hasil pengolahan SPSS.

3. Hasil Uji Koefisien Determinasi $\left(R^{2}\right)$

Dari Tabel 4.12 diatas dapat dilihat dari nilai $R$ Square $\left(R^{2}\right)$ menunjukkan nilai 0,942 yang berarti variabel independen dapat menjelaskan variabel dependen sebesar $94,2 \%$, sedangkan sisanya dapat dijelaskan oleh variabel lain yang tidak dimasukkan dalam model penelitian ini.

Tabel 6

Hasil Uji Koefisien Determinasi $\left(R^{2}\right)$

\begin{tabular}{|l|c|r|r|r|}
\hline Model & $R$ & $\begin{array}{c}R \\
\text { Square }\end{array}$ & $\begin{array}{c}\text { Adj. } R \\
\text { Square }\end{array}$ & $\begin{array}{l}\text { Std. Error } \\
\text { Estimate }\end{array}$ \\
\hline 1 & $.973 a$ & .947 & .942 & 388.95615 \\
\hline
\end{tabular}

Sumber: Hasil pengolahan SPSS. 
Permatasari, et al/Jurnal Ekonomi Syariah Teori dan Terapan Vol. 4 No. 7 Juli 2017: 587-598; PENGARUH VARIABEL MAKRO TERHADAP NILAI TUKAR RUPIAH ATAS DOLAR AS PERIODE 2012-2015

Pengaruh Jumlah Uang Beredar (JUB) Terhadap Nilai Tukar Rupiah Terhadap Dolar Tahun 2012-2015

Hasil penelitian menunjukkan bahwa jumlah vang beredar berpengaruh positif dan signifikan terhadap nilai tukar rupiah atas dolar AS periode 2012-2015. Hasil ini juga mendukung hasil penelitian yang dilakukan oleh Adwin Surja Atmadja (2002) bahwa variabel jumlah vang beredar memiliki pengaruh yang signifikan terhadap pergerakan nilai tukar rupiah atas dolar AS. Penelitian oleh Wahyu Ario Pratomo (2005) yang menyatakan bahwa jumlah vang beredar signifikan terhadap kurs dalam jangka pendek atau jangka panjang.

Hasil ini juga diperkuat dengan teori paritas daya beli (purchasing power parity theory) bahwa kenaikan penawaran vang akan menyebabkan inflasi di dalam negeri terhadap inflasi di luar negeri, hal ini mengakibatkan mata vang di dalam negeri menurun dibanding dengan mata vang di luar negeri. Semakin tinggi vang beredar domestik akan menyebabkan mata vang domestik terdepresiasi.

Pengaruh Imbal Hasil SBIS Terhadap Nilai Tukar Rupiah Terhadap Dolar Tahun 20122015

Hasil penelitian menunjukkan bahwa imbal hasil sertifikat Bank Indonesia syariah berpengaruh positif dan signifikan terhadap nilai tukar rupiah atas dolar AS periode 2012-2015.

Dilihat dari keberhasilan SBIS dalam menyerap kelebihan uang beredar, dapat dikatakan bahwa SBIS telah efektif dan mendatangkan manfaat dalam pengendalian moneter. Akan tetapi jika dilihat dari kesesuaian dengan semangat yang dibawa ekonomi islam yang mengedepankan keseimbangan antara perkembangan sektor riil dengan sektor keuangan, SBIS belum dapat membawa semangat tersebut. Sistem Ju'alah yang cukup menggiurkan dengan tingkat imbalan yang mengacu pada diskonto SBI menjadi hal yang menarik bagi perbankan untuk menyimpan dananya dalam bentuk SBIS. Hal ini tentu saja akan menyebabkan berkurangnya aliran vang untuk sektor produksi.

Terhambatnya kegiatan perekonomia pada sektor riil akan membuat produksi menurun sehingga dapat melemahkan nilai tukar mata uang domestik atau mata vang rupiah terdepresi.

\section{Pengaruh Ekspor Terhadap Nilai Tukar}

\section{Rupiah Terhadap Dolar Tahun 2012-2015}

Hasil penelitian menunjukkan bahwa ekspor tidak berpengaruh secara signifikan terhadap nilai tukar rupiah atas dolar AS periode 2012-2015. Hasil ini juga mendukung hasil penelitian yang dilakukan oleh Ari Usman Effendi (2012), yang menyatakan bahwa ekspor dan impor bersama-sama mempunyai pengaruh namun tidak signifikan terhadap nilai kurs rupiah atas dolar Amerika Serikat.

Untuk mampu mengekspor, suatu negara harus mampu menghasilkan barang dan jasa yang dapat bersaing di pasaran internasional dan perlu kurs valuta asing untuk melakukan kegiatan 
ekspor. Kegiatan ekspor dapat terhambat jika keadaan ekonomi suatu negara terganggu sehingga mengakibatkan ekspor turun dan impor akan meningkat.

Pengaruh Impor Terhadap Nilai Tukar Rupiah Atas dolar AS Tahun 2012-2015

Hasil penelitian menunjukkan bahwa impor tidak berpengaruh secara signifikan terhadap nilai tukar rupiah atas dolar AS periode 2012-2015. Hasil ini juga mendukung hasil penelitian yang dilakukan oleh Triyono (2008) bahwa berdasarkan analisis jangka pendek variabel impor tidak berpengaruh secara signifikan terhadap kurs sedangkan analisis jangka panjang variabel impor berpengaruh secara signifikan terhadap kurs. Nilai koefisien impor paling kecil pengaruhnya terhadap kurs dibanding nilai koefisien variabel yang lain karena pada periode penelitian terjadi penurunan permintaan negara Indonesia seiring dengan perlambatan ekonomi Indonesia.

Pengaruh JUB, Imbal Hasil SBIS, Ekspor, Impor Terhadap Nilai Tukar Rupiah Atas Dolar Tahun 2012-2015

Hasil penelitian menunjukkan bahwa secara bersama-sama atau simultan, variabel jumlah vang beredar, imbal hasil sertifikat Bank Indonesia syariah, ekspor, impor berpengaruh signifikan terhadap nilai tukar rupiah atas dolar AS pada periode Januari 2012 sampai Desember 2015.

Kebijakan nilai tukar uang dalam Islam dapat dikatakan menganut sistem mengambang terkendali (Managed
Floating), dimana nilai tukar adalah hasil dari kebijakan-kebijakan pemerintah karena pemerintah tidak mencampuri keseimbangan yang terjadi di pasar kecuali terjadi hal-hal yang mengganggu keseimbangan itu sendiri. Jadi, nilai tukar yang stabil merupakan hasil dari kebijakan pemerintah yang tepat. Dalam mengontrol kestabilan nilai rupiah, jumlah vang beredar merupakan salah satu faktor yang mempunyai peranan penting. Penawaran uang yang terlalu tinggi akan menyebabkan inflasi yang kemudian berakibat pada naiknya nilai mata vang asing terhadap mata vang dalam negeri.

Bank Indonesia menerbitkan dan menjual SBIS untuk menyerap kelebihan jumlah vang primer yang beredar. Ketika imbal hasil SBIS tinggi maka masyarakat akan tertarik untuk mengalokasikan dananya pada investasi jangka pendek SBIS dan menghambat aliran vang pada sektor riil yang membuat produksi menurun sehingga dapat melemahkan nilai tukar mata vang domestik.

Dari keterangan diatas maka dapat disimpulkan bahwa jumlah vang beredar yang terlalu tinggi di masyarakat akan mengakibatkan depresiasi nilai mata vang rupiah terhadap mata vang asing, imbal hasil SBIS yang tinggi akan menghambat aliran vang untuk sektor riil sehingga akan melemahkan nilai tukar mata vang domestik terhadap mata vang asing.

\section{SIMPULAN DAN SARAN}

Berdasarkan penelitian yang telah dilakukan, maka dapat disimpulkan: 
1. Hipotesis $H_{0}$ ditolak, dan $H_{1}$ diterima sehingga semua variabel independen secara simultan berpengaruh secara signifikan terhadap variabel terikat. Dari hasil tersebut maka dapat disimpulkan bahwa terdapat pengaruh variabel jumlah vang beredar (JUB), imbal hasil SBIS, impor, ekspor terhadap variabel nilai tukar rupiah atas dolar AS periode 20122015.

2. Variabel jumlah vang beredar dan imbal hasil SBIS berpengaruh signifikan terhadap nilai tukar rupiah atas dolar AS periode 2012-2015. Hal ini terjadi karena kenaikan penawaran vang menyebabkan inflasi di dalam negeri yang mengakibatkan mata vang di dalam negeri menurun dibandinng dengan mata vang di luar negeri. Semakin tinggi vang beredar akan menyebabkan mata vang domestik terdepresiasi. Imbal hasil yang diberikan $\mathrm{Bl}$ kepada BUS atas pembelian SBIS dapat menyebabkan BUS lebih tertarik dalam menyimpan kelebihan dananya dalam bentuk SBIS yang dapat mengurangi aliran pembiayaan pada sektor riil, sehingga kegiatan perekonomian akan terhambat dan menjadikan nilai mata vang domestik terdepresiasi karena pelemahan ekonomi.

3. Variabel ekspor dan impor tidak berpengaruh signifikan terhadap nilai tukar rupiah atas dolar AS periode 2012-2015. Hasil ini juga mendukung hasil penelitian yang dilakukan oleh
Ari Usman Effendi (2012), yang menyatakan bahwa ekspor dan impor bersama-sama tidak mempunyai pengaruh signifikan terhadap nilai tukar rupiah atas dolar Amerika Serikat. Nilai koefisien impor paling kecil pengaruhnya terhadap nilai tukar dibanding nilai koefisien variabel yang lain karena pada periode penelitian terjadi penurunan permintaan negara Indonesia terhadap barang impor seiring dengan perlambatan ekonomi Indonesia.

Berdasarkan penelitian yang telah dilakukan, maka saran yang dapat diberikan adalah sebagai berikut:

1. Pemerintah diharapkan dapat mengoptimalkan pertumbuhan ekonomi dengan meningkatkan ekspor dan membatasi impor agar mendorong stabilitas nilai tukar rupiah.

2. Bagi Bank Indonesia diharapkan dapat mengendalikan jumlah vang beredar melalui intrumen pasar terbuka (OPT) serta melakukan kebijakan dalam mengendalikan tingkat suku bunga yang menjadi acuan bagi Bank Umum Konvensional maupun Bank Umum Syariah dalam upaya menjaga stabilitas nilai tukar rupiah.

3. Bagi Bank Umum Syariah diharapkan mampu lebih agresif dalam penyaluran dana bagi sektor riil agar meningkatkan produksi dalam negeri 
Permatasari, et al/Jurnal Ekonomi Syariah Teori dan Terapan Vol. 4 No. 7 Juli 2017: 587-598; PENGARUH VARIABEL MAKRO TERHADAP NILAI TUKAR RUPIAH ATAS DOLAR AS PERIODE 2012-2015

sehingga dapat membantu menjaga kestabilan nilai tukar rupiah.

4. Bagi peneliti selanjutnya diharapkan dapat memperpanjang periode penelitian menjadi lebih dari empat tahun untuk melihat pengaruh dari variabel independen dalam jangka panjang terhadap variabel dependen, dan menambah variabelvariabel lain yang diduga berpengaruh terhadap nilai tukar rupiah atas dolar AS.

\section{DAFTAR PUSTAKA}

Al-Maliki, Abdurrahman, 2001, Politik Ekonomi Islam, Terj. Ibnu Sholah, AlIzzah, Bangil.

Atmaja, Surja Adwin. 2002. "Analisa Pergerakan Nilai Tukar Rupiah terhadap Dollar Amerika Setelah Diterapkannya Kebijakan Sistem Nilai Tukar Mengambang Bebas di Indonesia". Dalam Jurnal Ekonomi Akuntansi dan Keuangan, Volume 4 No. 1. Hal 69-78 Jakarta: Universitas Kristen Petra.

Bank Indonesia. Beberapa tahun edisi, Statistik Ekonomi-Keuangan Indonesia (SEKI). Jakarta: BI.

-------. Beberapa tahun edisi. Laporan Tahunan. Jakarta: Bank Indonesia.

-------. Kajian Stabilitas Keuangan (KSK) No.20, Maret 2013. Jakarta: BI

Chapra, M. Umer. 2000. Sistem Moneter Islam, Jakarta: Gema Insani Press.

Effendi, Ari Usman. 2012. Analisis Pengaruh Tingkat Inflasi, Tingkat Suku Bunga, Ekspor dan Impor Terhadap Nilai Kurs
Mata vang Rupiah Atas Dolar Amerika Serikat Tahun 1998-2012.

Ghozali, Imam. 2001. Aplikasi Analisis Multivariate Dengan Program SPSS. Semarang: Badan Penerbit Universitas Diponegoro.

Mishkin, Frederic S. 2008. Ekonomi Uang, Perbankan, dan Pasar Keuangan. Edisi Sembilan, Jilid 2. Jakarta : Salemba Empat

Nachrowi dan Usman. 2006. Manajemen Teori, Praktik dan Riset Pendidikan. Jakarta : PT Bumi Akasara

Nopirin, ph. D. 1987. Ekonomi Moneter Buku Dua. Edisi Kesatu. Yogyakarta:BPFE Yogyakarta.

Pratomo, Wahyu Ario. 2005. "Exchange Rate of Indonesia: Does Rupiah Overshoot?". Dalam Jurnal Ekonomi Pembangunan. Hal 1-15 Medan: Universitas Sumatera Utara.

Samuelson, Paul dan William D.Nordhaus. 2004. IImu Makroekonomi. Edisi 17. Jakarta: PT. Media Global Edukasi.

Sukirno, Sudono. 2004. Makroekonomi Teori Pengantar. Jakarta: PT. Raja Grafindo Persada.

-------. 2005. Makroekonomi Modern, Jakarta: PT. Raja Grafindo Persada.

Triyono. 2008. "Analisis Perubahan Kurs Rupiah terhadap Dollar Amerika". Jurnal Ekonomi Pembangunan, Volume 9 No. 2. Hal 156-167 Surakarta: Universitas Muhammadiyah Surakarta. www.bi.go.id, diakses pada 20 September 2016, 13:20.

www.bps.go.id, diakses 20 September 2016, 15.00 . 